\title{
STUDY OF CORRELATION BETWEEN ASSESSMENT OF RESIDENTS BY FACULTY AND BY NURSES
}

\author{
Shaurya Bajpai ${ }^{1}$, Ajay Lunawat², Sanjay Datey3
}

${ }^{1}$ Consultant Surgeon, Department of General Surgery, Sri Aurobindo Medical College and Postgraduate Institute, Indore, M. P.

2Professor, Department of General Surgery, Sri Aurobindo Medical College and Postgraduate Institute, Indore, M. P.

3Professor, Department of General Surgery, Sri Aurobindo Medical College and Postgraduate Institute, Indore, M. P.

\section{ABSTRACT}

\section{BACKGROUND}

Indian healthcare is facing severe resource shortage, which can only be overcome by innovative solutions. To understand the possibility of expanding the role of nurses in primary healthcare, we correlated the ability of senior nurses to assess residents' performance with residents' assessment by Faculty. We also identified the residents' opinion of senior nurses' advice in critical care to support our results.

The purpose of this study is to evaluate senior nurses' ability to assess a resident's performance, compare it with Faculty's assessment and identify the residents' opinion of senior nurses' advice.

\section{MATERIALS AND METHODS}

An observational study conducted from January 20 to February 11, 2018, including 27 residents and 4 faculty members of Department of General Surgery and 3 ICU senior nurses at a tertiary healthcare centre. Clinical Handover Assessment Tool (CHAT) was used to evaluate resident's performance. Residents were provided with a customised questionnaire to evaluate the senior nurses.

\section{RESULTS}

We found a strong, positive and statistically significant correlation between nurses' overall rating and the consultants' overall rating for the residents. Spearman rho rank correlation was statistically significant $(\rho=0.923 ; 0.929 ; 0.953$ for the three surgery department units respectively with $P=0.000)$. Kendall tau-b was found to be statistically significant $(\tau=0.866,0.817,0.880)$ for the three department units with $\mathrm{P}=0.002 ; 55.6 \%$ residents in unit $1,66.7 \%$ in unit 2 and $44.4 \%$ in unit 3 rated strong dependence on senior ICU/ ECU nurses for decision making and procedure learning in first 8 months of residency. 88.9\% residents in unit 1 and $66.7 \%$ residents in unit 2 and 3 felt more confident in the presence of a Senior Nurse while performing emergency procedures.

\section{CONCLUSION}

The present study shows that nurses have a similar cognisance, if not equal, to faculty in assessing a resident's performance in a clinical setting and residents have a positive outlook towards nursing advice in critical care.

\section{KEYWORDS}

Resident Performance Assessment, Senior Nurses, Faculty, Nursing Advice, Role of Nurses.

HOW TO CITE THIS ARTICLE: Bajpai S, Lunawat A, Datey S. Study of correlation between assessment of residents by faculty and by nurses. J. Evolution Med. Dent. Sci. 2018;7(11):1300-1307, DOI: 10.14260/jemds/2018/297

\section{BACKGROUND}

Resident doctors and nurses are the primary pillars of tertiary healthcare across the globe. Association between these two professions is perhaps the most vital and visible association in day-to-day working of an institution. Nurses and residents spend a considerable time of their work hours together, and this interdependent relationship plays a vital role in shaping up a resident's clinical skills and understanding of emergency and critical care. Nursing curriculum touches upon the aspects of medicine in a superficial manner in comparison to undergraduate curriculum of medical students, but with further graduate education and years of training nurses develop an understanding of medicine which is trusted by doctor's fraternity to manage and treat patient in emergency and

'Financial or Other Competing Interest': None.

Submission 21-02-2018, Peer Review 05-03-2018,

Acceptance 07-03-2018, Published 09-03-2018.

Corresponding Author:

Dr. Shaurya Bajpai,

CH-127, Scheme No. 74

Vijay Nagar, Indore (M. P.)

E-mail: shauryabajpai3@gmail.com

DOI: $10.14260 /$ jemds $/ 2018 / 297$

\section{(c) $(1) \ominus$}

critical medical conditions before the specialist's medical help arrives. In the first three months of residency when a recently admitted student is still alien to life-saving measures but is the first point of contact with patients reaching ICU and ECU after outpatient hours, the importance of nursing advice and clinical standing of an assistant senior nurse becomes pivotal. Not only in ensuring the delivery of immediate medical help to the patient, but also in providing an additional perspective and guidance to a resident. However, there is little to no interaction between medical and nursing students in classrooms and clinical teaching. There is a heavy emphasis on defined roles and hierarchy in Indian healthcare, especially in institutes. This rigid and archaic approach prevents path breaking solutions, which are required to resolve issues related to high cost of treatment and resource shortage in India. This study tries to draw a parallel between assessment of residents by an experienced ICU/ ECU nurse and by a faculty. It is to discuss the ability of nurses in understanding the clinical standing of residents, thus helping us understand in return a dimension of nurses' clinical ability. We also discuss a resident's perspective towards nurses and how much importance he/ she assigns in his/ her growth to nursing assistance in three years of training. This approach allows us not only to examine an unexplored aspect of 
nursing professionals, but also to discuss their future roles in ever evolving global healthcare.

\section{Aims and Objectives \\ Aim}

Assessment of residents' performance by senior nurses and by faculty and its correlation.

\section{Objectives}

a. Assessment of residents' performance by the senior nurses working in ICU/ ECU.

b. Assessment of residents' performance by the faculty members of the Department of General Surgery.

c. Identifying the outlook of residents of the Department of General Surgery towards nursing advice to enhance the discussion of correlation between first two objectives.

\section{MATERIALS AND METHODS}

An observational study of data collected from residents and faculty of General Surgery Department and ICU nurses, during January 20 to February 11, 2018 was done at a tertiary healthcare centre. The study was approved by Institutional Research Committee. The study included 27 postgraduates in Surgery Department, 4 faculty members and 3 Intensive Care Unit nurses by convenient sampling method. All the residents who have completed more than 8 months of training and have been posted in ICU were included in the study. Non-confirming residents who did not provide the verbal consent were excluded. The faculty members and nurses were randomly selected. Clinical Handover
Assessment Tool (CHAT) was used by faculty and nurses to evaluate resident's performance. Every assessing member was assigned a different room and two-hour time to complete the CHAT forms. Each form was scored on a Likert scale of 0 3; $0=$ Not performed competently, $1=$ Able to perform under firm direction, $2=$ Able to perform under modest direction and $3=$ Able to perform under minimal direction. Each faculty and nurse evaluated residents according to the unit residents posted in. No cross unit evaluation was done.

Residents were provided with a customised questionnaire for evaluation of quantitative date (rated on Likert scale) and qualitative data (using subjective questions), to assess resident's opinion towards nurses and their role in residents' clinical training. The data from the questionnaire and CHAT forms was transferred to the Microsoft Excel for further analysis. Online statistical software was used for finding out the ' $p$ ' value. Spearman rho rank correlation was applied to find out the correlation of ranking between the senior nurse and consultant of each unit, and Kendall tau-b rank correlation was applied to find out the concordance between the ratings done by senior nurse and consultant of each unit. Kendall tau-b value lies between 0 to 1 , where 0 means no concordance and 1 means perfect concordance. A p value of $<0.05$ was taken as statistically significant. The data obtained from residents was used to support the conclusion of this study. Financial inputs were taken care of by the investigator himself. As it was a noninvasive and observational study, verbal consent was obtained from each participant.

\section{RESULTS}

\begin{tabular}{|c|c|c|c|c|c|c|c|}
\hline \multirow{2}{*}{ Parameter } & \multirow{2}{*}{ Grading } & \multicolumn{2}{|c|}{ Unit 1} & \multicolumn{2}{|c|}{ Unit 2} & \multicolumn{2}{|c|}{ Unit 3} \\
\hline & & No. & $\%$ & No. & $\%$ & No. & $\%$ \\
\hline \multirow{4}{*}{ Identifies self and position } & 0 & 0 & 0.0 & 0 & 0.0 & 0 & 0.0 \\
\hline & 1 & 3 & 33.3 & 3 & 33.3 & 1 & 11.1 \\
\hline & 2 & 6 & 66.7 & 4 & 44.4 & 0 & 0.0 \\
\hline & 3 & 0 & 0.0 & 2 & 22.2 & 8 & 88.9 \\
\hline \multirow{4}{*}{ Identifies main problem } & 0 & 0 & 0.0 & 0 & 0.0 & 0 & 0.0 \\
\hline & 1 & 5 & 55.6 & 4 & 44.4 & 1 & 11.1 \\
\hline & 2 & 4 & 44.4 & 4 & 44.4 & 4 & 44.4 \\
\hline & 3 & 0 & 0.0 & 1 & 11.1 & 4 & 44.4 \\
\hline \multirow{4}{*}{ Gives appropriate history } & 0 & 0 & 0.0 & 0 & 0.0 & 0 & 0.0 \\
\hline & 1 & 5 & 55.6 & 4 & 44.4 & 3 & 33.3 \\
\hline & 2 & 2 & 22.2 & 4 & 44.4 & 3 & 33.3 \\
\hline & 3 & 2 & 22.2 & 1 & 11.1 & 3 & 33.4 \\
\hline \multirow{4}{*}{$\begin{array}{c}\text { Gives appropriate examination/ } \\
\text { observations }\end{array}$} & 0 & 0 & 0.0 & 1 & 11.1 & 0 & 0.0 \\
\hline & 1 & 3 & 33.3 & 3 & 33.3 & 2 & 22.2 \\
\hline & 2 & 6 & 66.7 & 4 & 44.4 & 4 & 44.4 \\
\hline & 3 & 0 & 0.0 & 1 & 11.1 & 3 & 33.3 \\
\hline \multirow{4}{*}{ Makes logical assessment } & 0 & 0 & 0.0 & 1 & 11.1 & 0 & 0.0 \\
\hline & 1 & 3 & 33.3 & 3 & 33.3 & 2 & 22.2 \\
\hline & 2 & 5 & 55.6 & 3 & 33.3 & 5 & 55.6 \\
\hline & 3 & 1 & 11.1 & 2 & 22.2 & 2 & 22.2 \\
\hline \multirow{4}{*}{ Makes clear recommendations } & 0 & 1 & 11.1 & 0 & 0.0 & 0 & 0.0 \\
\hline & 1 & 4 & 44.4 & 4 & 44.4 & 1 & 11.1 \\
\hline & 2 & 4 & 44.4 & 4 & 44.4 & 7 & 77.8 \\
\hline & 3 & 0 & 0.0 & 1 & 11.1 & 1 & 11.1 \\
\hline \multirow{4}{*}{$\begin{array}{c}\text { Global rating } \\
\text { How confident I am that I } \\
\text { received an accurate picture of } \\
\text { the patient? }\end{array}$} & 0 & 3 & 33.3 & 0 & 0.0 & 0 & 0.0 \\
\hline & 1 & 4 & 44.4 & 2 & 22.2 & 0 & 0.0 \\
\hline & 2 & 2 & 22.2 & 5 & 55.6 & 4 & 44.4 \\
\hline & 3 & 0 & 0.0 & 2 & 22.2 & 5 & 55.6 \\
\hline
\end{tabular}


The above table shows the distribution of residents according to assessment done by senior nursing staff according to Unit. The score was given using Likert Scale as 0- Not performed competently, 1- Able to perform under firm direction, 2- Able to perform under modest direction and 3- Able to perform under minimal direction.

\section{In Unit 1}

For the parameter "identifies self and position," there were 3 $(33.3 \%)$ residents that received score 1 and $6(66.7 \%)$ residents that received score 2 . Majority of the residents were able to identify self and position under modest direction.

For the parameter "identifies main problem," there were $5(55.6 \%)$ residents who received score 1 and 4 (44.4\%) residents who received score 2 . Majority of the residents were able to identify the main problem under modest direction.

For the parameter "gives appropriate history," there were $5(55.6 \%)$ residents who received score 1, 2 (22.2\%) residents who received score 2 and $2(22.2 \%)$ residents who received score 3 . Majority of the residents were able to give appropriate history under firm direction.

For the parameter "gives appropriate examination/observations," there were 3 (33.3\%) residents who received score 1 and $6(66.7 \%)$ residents who received score 2. Majority of the residents were able to give appropriate examination/observations under modest direction.

For the parameter "makes logical assessment" there were $3(33.3 \%)$ residents who received score 1, 5 (55.6\%) residents received score 2 and 1 (11.1\%) resident received score 3. Majority of the residents were able to make logical assessment under modest direction, while only $11.1 \%$ residents were able to make logical assessment under minimal direction.

For the parameter "makes clear recommendations" there was 1 (11.1\%) resident who received score $0,4(44.4 \%)$ residents received score 1 and 4 (44.4\%) residents received score 2. Majority of the residents were able to make clear recommendations under firm to modest direction.

For the parameter "global rating How confident I am that I received an accurate picture of the patient?," there were 3 (33.3\%) residents who received score 0,4 (44.4\%) residents received score 1 and $2(22.2 \%)$ residents received score 2 . Majority of the residents were able to give accurate picture of the patient under firm direction only.

\section{In Unit 2}

For the parameter "identifies self and position," there were 3 $(33.3 \%)$ residents who received score $1,4(44.4 \%)$ residents who received score 2 and $2(22.2 \%)$ residents who received score 3. Majority of the residents were able to identify self and position under modest direction.

For the parameter "identifies main problem," there were $4(44.4 \%)$ residents who received score 1, 4 (44.4\%) residents who received score 2 and 1 (11.1\%) resident who received score 3 . Majority of the residents were able to identify the main problem under firm-to-modest direction.

For the parameter "gives appropriate history" there were $4(44.4 \%)$ residents who received score 1, 4 (44.4\%) residents who received score 2 and 1 (11.1\%) resident who received score 3 . Majority of the residents were able to give appropriate history under firm-to-modest direction, while
$11.1 \%$ residents were able to give appropriate history under minimal direction.

For the parameter "gives appropriate examination/observations," there was 1 (11.1\%) resident who received score $0,3(33.3 \%)$ residents who received score 2, 4 (44.4\%) residents who received score 2 and 1 $(11.1 \%)$ resident who received score 3 . Majority of the residents were able to give appropriate examination/observations under modest direction, while $11.1 \%$ residents were able to give appropriate examination/observations under minimal direction.

For the parameter "makes logical assessment," there was $1(11.1 \%)$ resident who received score $0,3(33.3 \%)$ residents who received score $1,3(33.3 \%)$ residents who received score 2 and $2(22.2 \%)$ residents who received score 3 . Majority of the residents were able to make logical assessment under firm-to-modest direction, while only $22.2 \%$ residents were able to make logical assessment under minimal direction.

For the parameter "makes a clear recommendation," there were $4(44.4 \%)$ residents who received score 1,4 (44.4\%) residents who received score 2 and 1 (11.1\%) resident who received score 3. Majority of the residents were able to make a clear recommendation under firm-to-modest direction, while only $11.1 \%$ residents were able to make a clear recommendation under minimal direction.

For the parameter "global rating How confident I am that I received an accurate picture of the patient?," there were 2 $(22.2 \%)$ residents who received score $1,5(55.6 \%)$ residents who received score 2 and $2(22.2 \%)$ residents who received score 3. Majority of the residents were able to accurately picture the patient under firm-to-modest direction, while $22.2 \%$ residents were able to accurately picture the patient under minimal direction.

\section{In Unit 3}

For the parameter "identifies self and position," there were 1 (11.1\%) resident who received score 1 and 8 (88.9\%) residents who received score 3 . Majority of the residents were able to identify self and position under minimal direction.

For the parameter "identifies main problem," there was 1 (11.1\%) resident who received score 1, 4 (44.4\%) residents received score 2 and 4 (44.4\%) residents received score 3. Majority of the residents were able to identify the main problem under modest-to-minimal direction.

For the parameter "gives appropriate history," there were 3 (33.3\%) residents who received score 1, 3 (33.3\%) residents who received score 2 and 3 (33.4\%) residents who received score 3. Majority of the residents were able to give appropriate history under modest-to-minimal direction.

For the parameter that "gives appropriate examination/observations, there were 2 (22.2\%) residents who received score $1,4(44.4 \%)$ residents who received score 2 and 3 (33.3\%) residents who received score 3 . Majority of the residents were able to give appropriate examination/ observations under modest direction, while 
$33.3 \%$ residents were able to give appropriate examination/observations under minimal direction.

For the parameter "makes logical assessment," there were $2(22.2 \%)$ residents who received score 1, 5 (55.6\%) residents received score 2 and $2(22.2 \%)$ residents received score 3. Majority of the residents were able to make logical assessment under modest direction, while only $22.2 \%$ residents were able to make logical assessment under minimal direction.

For the parameter "makes clear recommendations," there was 1 (11.1\%) resident who received score 1, 7 (77.8\%) residents received score 2 and 1 (11.1\%) resident received score 3. Majority of the residents were able to make a clear recommendation under modest direction, while only $11.1 \%$ residents were able to make a clear recommendation under minimal direction.

For the parameter "global rating, How confident I am that I received an accurate picture of the patient?," there were 4 (44.4\%) residents who received score 2 and 5 (55.6\%) residents who received score 3 . Majority of the residents were able to accurately picture the patient under minimal direction.

\begin{tabular}{|c|c|c|c|c|c|c|c|}
\hline \multirow{2}{*}{ Parameter } & \multirow{2}{*}{ Grading } & \multicolumn{2}{|c|}{ Unit 1} & \multicolumn{2}{|c|}{ Unit 2} & \multicolumn{2}{|c|}{ Unit 3} \\
\hline & & No. & $\%$ & No. & $\%$ & No. & $\%$ \\
\hline \multirow{4}{*}{ Identifies self and position } & 0 & 1 & 11.1 & 1 & 11.1 & 0 & 0.0 \\
\hline & 1 & 3 & 33.3 & 2 & 22.2 & 1 & 11.1 \\
\hline & 2 & 4 & 44.4 & 6 & 66.7 & 2 & 22.2 \\
\hline & 3 & 1 & 11.1 & 0 & 0.0 & 6 & 66.7 \\
\hline \multirow{4}{*}{ Identifies main problem } & 0 & 0 & 0.0 & 0 & 0.0 & 0 & 0.0 \\
\hline & 1 & 3 & 33.3 & 4 & 44.4 & 2 & 22.2 \\
\hline & 2 & 4 & 44.4 & 4 & 44.4 & 6 & 66.7 \\
\hline & 3 & 2 & 22.2 & 1 & 11.1 & 1 & 11.1 \\
\hline \multirow{4}{*}{ Gives appropriate history } & 0 & 0 & 0.0 & 0 & 0.0 & 0 & 0.0 \\
\hline & 1 & 4 & 44.4 & 3 & 33.3 & 2 & 22.2 \\
\hline & 2 & 2 & 22.2 & 2 & 22.2 & 5 & 55.6 \\
\hline & 3 & 3 & 33.3 & 4 & 44.4 & 2 & 22.2 \\
\hline \multirow{4}{*}{$\begin{array}{c}\text { Gives appropriate examination/ } \\
\text { observations }\end{array}$} & 0 & 0 & 0.0 & 1 & 11.1 & 0 & 0.0 \\
\hline & 1 & 3 & 33.3 & 6 & 66.7 & 0 & 0.0 \\
\hline & 2 & 6 & 66.7 & 2 & 22.2 & 4 & 44.4 \\
\hline & 3 & 0 & 0.0 & 0 & 0.0 & 5 & 55.6 \\
\hline \multirow{4}{*}{ Makes logical assessment } & 0 & 0 & 0.0 & 1 & 11.1 & 0 & 0.0 \\
\hline & 1 & 5 & 55.6 & 6 & 66.7 & 0 & 0.0 \\
\hline & 2 & 3 & 33.3 & 1 & 11.1 & 5 & 55.6 \\
\hline & 3 & 1 & 11.1 & 1 & 11.1 & 4 & 44.4 \\
\hline \multirow{4}{*}{ Makes clear recommendations } & 0 & 0 & 0.0 & 1 & 11.1 & 0 & 0.0 \\
\hline & 1 & 4 & 44.4 & 4 & 44.4 & 2 & 22.2 \\
\hline & 2 & 2 & 22.2 & 4 & 44.4 & 4 & 44.4 \\
\hline & 3 & 3 & 33.3 & 0 & 0.0 & 3 & 33.3 \\
\hline \multirow{4}{*}{$\begin{array}{c}\text { Global Rating } \\
\text { How Confident I am that I } \\
\text { received an accurate Picture of } \\
\text { the Patient? }\end{array}$} & 0 & 0 & 0.0 & 1 & 11.1 & 0 & 0.0 \\
\hline & 1 & 4 & 44.4 & 4 & 44.4 & 2 & 22.2 \\
\hline & 2 & 4 & 44.4 & 2 & 22.2 & 3 & 33.3 \\
\hline & 3 & 1 & 11.1 & 2 & 22.2 & 4 & 44.4 \\
\hline
\end{tabular}

The above table shows the distribution of residents according to assessment done by consultants according to Unit.

\section{In Unit 1}

For the parameter "identifies self and position," there was 1 (11.1\%) resident who received score 0,3 (33.3\%) residents received score $1,4(44.4 \%)$ residents received score 2 and 1 (11.1\%) resident received score 3. Majority of the residents were able to identify self and position under modest direction, while only $11.1 \%$ residents were able to identify self and position under minimal direction.

For the parameter "identifies main problem" there were 3 (33.3\%) residents who received score $1,4(44.4 \%)$ residents who received score 2 and $2(22.2 \%)$ residents who received score 3 . Majority of the residents were able to identify the main problem under modest direction, while $22.2 \%$ residents were able to identify the main problem under minimal direction.

For the parameter "gives appropriate history" there were $4(44.4 \%)$ residents who received score 1, 2 (22.2\%) residents who received score 2 and 3 (33.3\%) residents who received score 3 . Majority of the residents were able to give appropriate history under firm direction, while $33.3 \%$ residents were able to give appropriate history under minimal direction.

For the parameter "gives appropriate examination/observations," there were $3(33.3 \%)$ residents who received score 1 and 6 (66.7\%) residents who received score 2. Majority of the residents were able to give appropriate examination/observations under modest direction.

For the parameter "makes logical assessment" there were $5(55.6 \%)$ residents who received score 1, 3 (33.3\%) residents who received score 2 and $1(11.1 \%)$ resident who received score 3. Majority of the residents were able to make logical assessment under firm direction, while only $11.1 \%$ residents were able to make logical assessment under minimal direction. 
For the parameter "makes clear recommendations" there were $4(44.4 \%)$ residents who received score 1, 2 (22.2\%) residents who received score 2 and 3 (33.3\%) residents who received score 3 . Majority of the residents were able to make clear recommendations under firm direction, while 33.3\% residents were able to make clear recommendations under minimal direction.

For the parameter "global rating How confident I am that I received an accurate picture of the patient?," there were 4 $(44.4 \%)$ residents who received score $1,4(44.4 \%)$ residents who received score 2 and $1(11.1 \%)$ resident who received score 3. Majority of the residents were able to give accurate picture of the patient under firm-to-modest direction, while $11.1 \%$ residents were able to give accurate picture of the patient under minimal direction.

\section{In Unit 2}

For the parameter "identifies self and position" there was 1 (11.1\%) resident who received score 0, 2 (22.2\%) residents who received score 1 and $6(66.7 \%)$ residents who received score 2. Majority of the residents were able to identify self and position under modest direction.

For the parameter "identifies main problem" there were 4 $(44.4 \%)$ residents who received score $1,4(44.4 \%)$ residents who received score 2 and $1(11.1 \%)$ resident who received score 3. Majority of the residents were able to identify the main problem under firm-to-modest direction, while 11.1\% residents were able to identify the main problem under minimal direction.

For the parameter "gives appropriate history" there were $3(33.3 \%)$ residents who received score 1, 2 (22.2\%) residents who received score 2 and 4 (44.4\%) residents who received score 3 . Majority of the residents were able to give appropriate history under minimal direction.

For the parameter "gives appropriate examination/observations" there was 1 (11.1\%) resident who received score $0,6(66.7 \%)$ residents who received score 2 and $2(22.2 \%)$ residents who received score 2 . Majority of the residents were able to give appropriate examination/observations under firm direction.

For the parameter "makes logical assessment" there was $1(11.1 \%)$ resident who received score $0,6(66.7 \%)$ residents who received score $1,1(11.1 \%)$ resident who received score 2 and $1(11.1 \%)$ resident who received score 3. Majority of the residents were able to make logical assessment under firm direction, while only $11.1 \%$ residents were able to make logical assessment under minimal direction.

For the parameter "makes clear recommendations" there was 1 (11.1\%) resident who received score 0,4 (44.4\%) residents who received score 1 and $4(44.4 \%)$ residents who received score 2 . Majority of the residents were able to make clear recommendations under firm-to-modest direction.
For the parameter "global rating How confident I am that I received an accurate picture of the patient?," there was 1 (11.1\%) resident who received score 1,4 (44.4\%) residents who received score $1,2(22.2 \%)$ residents who received score 2 and $2(22.2 \%)$ residents who received score 3 . Majority of the residents were able to accurately picture the patient under firm direction, while $22.2 \%$ residents were able to accurately picture the patient under minimal direction.

\section{In Unit 3}

For the parameter "identifies self and position" there was 1 $(11.1 \%)$ resident who received score $1,2(22.2 \%)$ residents who received score 2 and $6(66.7 \%)$ residents who received score 3. Majority of the residents were able to identify self and position under minimal direction.

For the parameter "identifies main problem" there were 2 $(22.2 \%)$ residents who received score $1,6(66.7 \%)$ residents who received score 2 and $1(11.1 \%)$ resident who received score 3. Majority of the residents were able to identify the main problem under modest direction, while $11.1 \%$ residents were able to identify the main problem under minimal direction.

For the parameter "gives appropriate history" there were $2(22.2 \%)$ residents who received score 1, 5 (55.6\%) residents who received score 2 and $2(22.2 \%)$ residents who received score 3 . Majority of the residents were able to give appropriate history under modest direction, while $22.2 \%$ residents were able to give appropriate history under minimal direction.

For the parameter "gives appropriate examination/observation" there were $4(44.4 \%)$ residents who received score 2 and 5 (55.6\%) residents who received score 3. Majority of the residents were able to give appropriate examination/observations under minimal direction.

For the parameter "makes logical assessment" there were 5 (55.6\%) residents who received score 2 and 4 (44.4\%) residents who received score 3 . Majority of the residents were able to make logical assessment under modest direction, while $44.4 \%$ residents were able to make logical assessment under minimal direction.

For the parameter "makes clear recommendations" there were $2(22.2 \%)$ residents who received score 1, 4 (44.4\%) residents who received score 2 and 3 (33.3\%) residents who received score 3 . Majority of the residents were able to make clear recommendations under modest direction, while $33.3 \%$ residents were able to make clear recommendations under minimal direction.

For the parameter "global rating How confident I am that I received an accurate picture of the patient?" there were 2 $(22.2 \%)$ residents who received score $1,3(33.3 \%)$ residents who received score 2 and 4 (44.4\%) residents who received score 3. Majority of the residents were able to accurately picture the patient under minimal direction.

\begin{tabular}{|c|c|c|c|c|c|c|c|}
\hline \multirow{2}{*}{ Parameter } & \multirow{2}{*}{ Grading } & \multicolumn{2}{|c|}{ Unit 1 } & \multicolumn{2}{c|}{ Unit 2 } & \multicolumn{2}{c|}{ Unit 3 } \\
\cline { 3 - 7 } & & No. & \% & No. & No. & \% \\
\hline How will you describe your & & & & & & & \\
dependence on senior nurse & 1 - Strong dependence & 6 & 66.7 & 5 & 55.6 & 4 & 44.4 \\
in ICU/ ECU for procedure & 2 - Some dependence & 2 & 22.2 & 2 & 22.2 & 4 & 44.4 \\
learning and decision & 3 - Weak dependence & 1 & 11.1 & 2 & 22.2 & 1 & 11.1 \\
making in first 3 months of & 4- No dependence & 0 & 0.0 & 0 & 0.0 & 0 & 0.0 \\
residency? & & & & & & & \\
\hline
\end{tabular}




\begin{tabular}{|c|c|c|c|c|c|c|c|}
\hline $\begin{array}{c}\text { Do you feel more confident } \\
\text { in the presence of a Senior } \\
\text { Nurse while performing } \\
\text { procedures and taking key } \\
\text { decisions without any } \\
\text { guidance and participation } \\
\text { from seniors or peers, if yes, } \\
\text { then why? }\end{array}$ & $\begin{array}{l}1-\text { Yes } \\
2-\text { No }\end{array}$ & $\begin{array}{l}8 \\
1\end{array}$ & $\begin{array}{l}88.9 \\
11.1\end{array}$ & $\begin{array}{l}6 \\
3\end{array}$ & $\begin{array}{l}66.7 \\
33.3\end{array}$ & $\begin{array}{l}6 \\
3\end{array}$ & $\begin{array}{l}66.7 \\
33.3\end{array}$ \\
\hline $\begin{array}{l}\text { Do you trust an on-duty } \\
\text { senior nurse for emergency } \\
\text { management of a critical } \\
\text { patient before first doctor } \\
\text { contact? }\end{array}$ & $\begin{array}{c}1 \text { - Strongly trust } \\
2 \text { - Some trust } \\
3 \text { - Weak trust } \\
4 \text { - No trust }\end{array}$ & $\begin{array}{l}3 \\
5 \\
1 \\
0\end{array}$ & $\begin{array}{c}33.3 \\
55.6 \\
11.1 \\
0.0\end{array}$ & $\begin{array}{l}1 \\
7 \\
1 \\
0\end{array}$ & $\begin{array}{c}11.1 \\
77.8 \\
11.1 \\
0.0\end{array}$ & $\begin{array}{l}0 \\
6 \\
1 \\
2\end{array}$ & $\begin{array}{l}0.0 \\
66.7 \\
11.1 \\
22.2\end{array}$ \\
\hline $\begin{array}{c}\text { How will you rate charting of } \\
\text { BP/ Pulse/ Temperature/ } \\
\text { ICD collection } 4 \text { hourly by a } \\
\text { Senior ICU nurse? }\end{array}$ & $\begin{array}{c}1 \text { - Exceptional } \\
2 \text { - Above average } \\
3 \text { - Average } \\
4 \text { - Below average } \\
5 \text { - Poor }\end{array}$ & $\begin{array}{l}2 \\
7 \\
0 \\
0 \\
0\end{array}$ & $\begin{array}{c}22.2 \\
77.8 \\
0.0 \\
0.0 \\
0.0\end{array}$ & $\begin{array}{l}2 \\
2 \\
5 \\
0 \\
0\end{array}$ & $\begin{array}{c}22.2 \\
22.2 \\
55.6 \\
0.0 \\
0.0\end{array}$ & $\begin{array}{l}5 \\
2 \\
2 \\
0 \\
0\end{array}$ & $\begin{array}{c}55.6 \\
22.2 \\
22.2 \\
0.0 \\
0.0\end{array}$ \\
\hline $\begin{array}{c}\text { How will you rate patient- } \\
\text { senior nurse communication } \\
\text { in your presence? }\end{array}$ & $\begin{array}{c}1 \text { - Exceptional } \\
2 \text { - Above average } \\
3 \text { - Average } \\
4 \text { - Below average } \\
5 \text { - Poor }\end{array}$ & $\begin{array}{l}2 \\
6 \\
1 \\
0 \\
0\end{array}$ & $\begin{array}{c}22.2 \\
66.7 \\
11.1 \\
0.0 \\
0.0\end{array}$ & $\begin{array}{l}1 \\
1 \\
6 \\
1 \\
0\end{array}$ & $\begin{array}{c}11.1 \\
11.1 \\
66.7 \\
11.1 \\
0.0\end{array}$ & $\begin{array}{l}2 \\
1 \\
6 \\
0 \\
0\end{array}$ & $\begin{array}{c}22.2 \\
11.1 \\
66.7 \\
0.0 \\
0.0\end{array}$ \\
\hline
\end{tabular}

The above table shows the distribution of residents according to assessment done by consultants according to Unit.

\section{In Unit 1}

For the parameter "How will you describe your dependence on senior nurse in ICU/ ECU for procedure learning and decision making in first 3 months of residency?" 6 (66.7\%) residents rated strong dependence, $2(22.2 \%)$ residents rated some dependence and $1(11.1 \%)$ resident rated weak dependence.

For the parameter "Do you feel more confident in the presence of a Senior Nurse while performing procedures and taking key decisions without any guidance and participation from seniors or peers, if yes, then why?" $8(88.9 \%)$ residents rated yes, while only $1(11.1 \%)$ resident rated as no.

For the parameter "Do you trust an on-duty senior nurse for emergency management of a critical patient before first doctor contact?" $3(33.3 \%)$ residents rated strongly trust, 5 $(55.6 \%)$ rated some trust and $1(11.1 \%)$ resident rated weak trust.

For the parameter "How will you rate charting of BP/ Pulse/ Temperature/ ICD collection 4 hourly by a Senior ICU nurse?" 2 (22.2\%) residents rated as exceptional and 7 $(77.8 \%)$ residents rated as above average.

For the parameter "How will you rate patient-senior nurse communication in your presence? 2 (22.2\%) residents rated as exceptional, 6 (66.7\%) residents rated as above average and $1(11.1 \%)$ resident rated as average.

\section{In Unit 2}

For the parameter "How will you describe your dependence on senior nurse in ICU/ ECU for procedure learning and decision making in first 3 months of residency?" 5 (55.6\%) residents rated strong dependence, $2(22.2 \%)$ residents rated some dependence and $2(22.2 \%)$ residents rated weak dependence.

For the parameter "Do you feel more confident in the presence of a Senior Nurse while performing procedures and taking key decisions without any guidance and participation from seniors or peers, if yes, then why?" $6(66.7 \%)$ residents rated yes, while only 3 (33.3\%) residents rated as no.

For the parameter "Do you trust an on-duty senior nurse for emergency management of a critical patient before first doctor contact?" 1 (11.1\%) resident rated strongly trust, 7 $(77.8 \%)$ rated some trust and $1(11.1 \%)$ resident rated weak trust.

For the parameter "How will you rate charting of BP/ Pulse/ Temperature/ ICD collection 4 hourly by a Senior ICU nurse?" 2 (22.2\%) residents rated as exceptional, 2 (22.2\%) residents rated as above average and 5 (55.6\%) residents rated as average.

For the parameter "How will you rate patient-senior nurse communication in your presence?" 1 (11.1\%) resident rated as exceptional, $1(11.1 \%)$ resident rated as above average, $6(66.7 \%)$ resident rated as average and $1(11.1 \%)$ resident rated as below average.

\section{In Unit 3}

For the parameter "How will you describe your dependence on senior nurse in ICU/ ECU for procedure learning and decision making in first 3 months of residency?" 4 (44.4\%) residents rated strong dependence, 4 (44.4\%) residents rated some dependence and $1(11.1 \%)$ resident rated weak dependence.

For the parameter "Do you feel more confident in the presence of a Senior Nurse while performing procedures and taking key decisions without any guidance and participation from seniors or peers, if yes, then why?" $6(66.7 \%)$ residents rated yes, while only $3(33.3 \%)$ residents rated as no.

For the parameter "Do you trust an on-duty senior nurse for emergency management of a critical patient before first doctor contact?" 6 (66.7\%) rated some trust, 1 (11.1\%) resident rated weak trust and $2(22.2 \%)$ residents rated as no trust. 
For the parameter "How will you rate charting of BP/ Pulse/ Temperature/ ICD collection 4 hourly by a Senior ICU nurse?" 5 (55.6\%) residents rated as exceptional, 2 (22.2\%) residents rated as above average and $2(22.2 \%)$ residents rated as average.

For the parameter "How will you rate patient-senior nurse communication in your presence?" $2(22.2 \%)$ residents rated as exceptional, $1(11.1 \%)$ resident rated as above average and $6(66.7 \%)$ resident rated as average.

\begin{tabular}{|c|c|c|c|c|}
\hline Unit & Pair & $\begin{array}{c}\text { Spearman } \\
\text { Rho }\end{array}$ & $\begin{array}{c}\text { P } \\
\text { value }\end{array}$ & Interpretation \\
\hline Unit 1 & $\begin{array}{c}\text { Nurse's overall } \\
\text { rating - } \\
\text { Consultant's } \\
\text { overall rating }\end{array}$ & 0.923 & $0.000^{*}$ & $\begin{array}{c}\text { Positive, strong, } \\
\text { statistically } \\
\text { significant } \\
\text { correlation }\end{array}$ \\
\hline Unit 2 & $\begin{array}{c}\text { Nurse's overall } \\
\text { rating - } \\
\text { Consultant's } \\
\text { overall rating }\end{array}$ & 0.929 & $0.000^{*}$ & $\begin{array}{c}\text { Positive, strong, } \\
\text { statistically } \\
\text { significant } \\
\text { correlation }\end{array}$ \\
\hline Unit 3 & $\begin{array}{c}\text { Nurse's overall } \\
\text { rating - } \\
\text { Consultant's } \\
\text { overall rating }\end{array}$ & 0.953 & $0.000^{*}$ & $\begin{array}{c}\text { Positive, strong, } \\
\text { statistically } \\
\text { significant } \\
\text { correlation }\end{array}$ \\
\hline Table 4. Correlation of Overall Rating between Senior \\
Nurses and Consultants according to Units \\
\hline \multicolumn{4}{|c|}{}
\end{tabular}

Spearman rho Rank Correlation Test Applied. P value < 0.05 was taken as Statistically Significant

There is a statistically significant correlation between the nurses' overall rating and consultants' overall rating for the residents for each unit, showing that the assessment done by the senior nurses and the consultants for the resident doctors working in the Department of Surgery correlate very strongly for the residents of each unit.

\begin{tabular}{|c|c|c|c|c|}
\hline Unit & Pair & $\begin{array}{c}\text { Kendall } \\
\text { tau-b }\end{array}$ & $\begin{array}{c}\mathbf{P} \\
\text { value }\end{array}$ & Interpretation \\
\hline Unit 1 & $\begin{array}{c}\text { Nurse's } \\
\text { overall rating } \\
- \\
\text { Consultant's } \\
\text { overall rating }\end{array}$ & 0.866 & $0.002^{*}$ & \begin{tabular}{|c|} 
Statistically \\
significant high \\
concordance seen \\
between the \\
nurse's and \\
consultant's overall \\
rating for the \\
residents of Unit 1
\end{tabular} \\
\hline Unit 2 & $\begin{array}{c}\text { Nurse's } \\
\text { overall rating } \\
- \\
\text { Consultant's } \\
\text { overall rating }\end{array}$ & 0.817 & $0.002^{*}$ & \begin{tabular}{|} 
Statistically \\
significant high \\
concordance seen \\
between the \\
nurse's and \\
consultant's overall \\
rating for the \\
residents of Unit 2
\end{tabular} \\
\hline Unit 3 & $\begin{array}{c}\text { Nurse's } \\
\text { overall rating } \\
- \\
\text { Consultant's } \\
\text { overall rating }\end{array}$ & 0.880 & $0.002^{*}$ & \begin{tabular}{|} 
Statistically \\
significant high \\
concordance seen \\
between the \\
nurse's and \\
consultant's overall \\
rating for the \\
residents of Unit 3
\end{tabular} \\
\hline \multicolumn{5}{|c|}{$\begin{array}{c}\text { Table 5. Concordance of Overall Rating between Senior } \\
\text { Nurses and Consultants according to Units }\end{array}$} \\
\hline
\end{tabular}

Kendall tau-b Rank's Correlation test applied. P value < 0.05 was taken as statistically significant.

To find out the concordance between the rating done by senior nurses and consultants of residents of the Department of General Surgery for each unit, Kendall tau-b rank Correlation test was applied.

In all the three units, there was a very statistically significant high concordance seen between the senior nurse's rating and the consultant's rating of the residents of Department of General Surgery.

\section{DISCUSSION}

Residents get into their respective specialties with a basic understanding of the clinical work and patient-doctor interaction. For three years they are not only immersed in an academic dimension, but also trained rigorously in clinical dimension. Faculty is a witness to their growth and consequently develops a cognisance towards every candidate. This cognisance is based on faculty's clinical experience and interpersonal interactions with residents. Nurses are the only other entity working with and observing residents in every department. In the initial days of his training residents are learning not only from senior residents, but also from senior nurses. ${ }^{1}$ ICU management is arguably the most difficult and crucial part of a resident's training. Several studies have shown the ability of nurses to evaluate resident's humanistic behaviour.,2,3 This study makes an attempt to understand a resident's growth in terms of both clinical and interpersonal, and ability of nurses to evaluate a resident's performance. The objective of this study is to draw a parallel between nurses and doctors, and understand the possibility of using nurses as medical force to resolve the scarcity of medical help in remote areas of our country.

In 2002, Davis et al performed a study in which 16 Obstetrics and Gynaecology residents were evaluated by faculty, peer, self and nurses with an aim to determine if the addition of peer, self and nurse evaluators would enhance faculty assessment of resident's performance. The reliability of faculty ratings was good-to-excellent, whereas resident ratings showed excellent reliability for all three measured variables. Ratings provided by the nurses were the least reliable of the groups rating the residents. ${ }^{4}$

In 1996, Ryan et al carried out the 'Reliability of faculty clinical evaluations of non-emergency medicine residents during emergency department rotations,' in which they included 66 residents who were rotated through the ED, yielding a total of 401 evaluations. The study found a significant variability in the scoring patterns of individual evaluators. The evaluators in this study showed large variations in both leniency (as measured by their mean score) and range restriction (as measured by their SD). ${ }^{5}$

In 2004, Wood et al compared patient, faculty and selfassessment of radiology resident's performance. Correlations between resident-with-patient, resident-with-faculty and patient-with-faculty ratings for the 56 interactions were -0.06 $(\mathrm{P}=.64), 0.31(\mathrm{P}<.02)$ and $0.45(\mathrm{P}<.0006)$, respectively. Pearson correlation coefficients showed significant correlation $(\mathrm{r}=0.70)$ between the faculty global rating and patient 360-degree scores $(\mathrm{P}=.08){ }^{6}$

In 1989, Risucci et al compared ratings of surgical residents by self, supervisors and peers. Results indicated 
that overall ratings by peers and supervisors were highly intercorrelated $(\mathrm{r}=0.92$; $\mathrm{P}$ less than 0.001$){ }^{7}$

In 1998, Johnson et al made a comparison of self, nurse and physician assessment of residents rotating through an intensive care unit. They found many similarities and some differences between physicians' and nurses' evaluations of residents. ${ }^{8}$

In our study, CHAT forms ${ }^{9}$ were used to assess residents and were further evaluated to find a correlation between resident assessment by nurses and faculty. Spearman rho rank correlation was statistically significant $(\rho=0.923 ; 0.929$; 0.953 for the three surgery department units respectively and $\mathrm{P}=0.000$ for the three surgery department units evaluated separately). Kendall tau-b was found to be statistically significant $(\tau=0.866,0.817,0.880)$ for the three department units with $\mathrm{P}=0.002$.

In 2017, Kurtzman et al made a comparison of Nurse Practitioners, Physician Assistants and Primary Care Physicians' Patterns of Practice and Quality of Care in Health Centres. Across the outcomes studied, results suggest that Nurse Practitioner and Physician Assistant care were largely comparable to Primary Care Physician care in Health Centres. ${ }^{10}$

In our study $55.6 \%$ residents in unit $1,66.7 \%$ in unit 2 and $44.4 \%$ in unit 3 rated strong dependence on senior ICU/ECU nurses for decision making and procedure learning in first 8 months of their residency. $88.9 \%$ residents in unit 1 and $66.7 \%$ residents in unit 2 and 3 felt more confident in the presence of a Senior Nurse, while performing emergency procedures and taking key decisions without any guidance and participation from seniors or peers. $33.3 \%$ residents in unit 1 strongly trusted an on-duty senior nurse for emergency management of a critical patient before first doctor contact. This shows that residents appreciate nurses' clinical skills and value nurses' experience in critical care setting, not only for patient management but also for their training.

Areas where residents acknowledged that nurses' experience helped them learn were: Resuscitation of burn patients, understanding ventilator management, decision making for life saving procedures such as tracheostomy, emergency intubation and controlling sudden arterial spurt.

The present study shows that nurses have a similar cognisance, if not equal to faculty in assessing a resident's performance in a clinical setting.

The acknowledgement of importance of nursing advice and experience in critical medical conditions by residents and positive results obtained from this study indicate that a larger role can be carved out for senior nurses by subjecting them to additional academic and clinical training for resolving long pending healthcare lacunae.

\section{CONCLUSION}

The present study concludes that the assessment of surgery residents by the senior nurses well correlated with the assessment of the residents done by the consultants. Residents feel more confident while performing critical procedures in the presence of an experienced nurse. Residents trust senior nurses with emergency management of patients before a doctor arrives.

At present, we believe that there is a scope for widening role of nurses in Indian healthcare setup.

\section{ACKNOWLEDGEMENTS}

We would like to thank all the residents of the Department of General Surgery, Faculty of Department of General Surgery, Senior Nursing Staff and Librarian of the institute for their active participation and cooperation throughout the study.

\section{REFERENCES}

[1] Muller-Juge V, Cullati S, Blondon KS, et al. Interprofessional collaboration between residents and nurses in general internal medicine: a qualitative study on behaviours enhancing teamwork quality. PLoS One 2014;9(4):e96160.

[2] Linn LS, Oye RK, Cope DW, et al. Use of non-physician staff to evaluate humanistic behavior of internal medicine residents and faculty members. J Med Educ 1986;61(11):918-20.

[3] Butterfield PS, Mazzaferri EL, Sachs LA. Nurses as evaluators of the humanistic behavior of internal medicine residents. J Med Educ 1987;62(10):842-9.

[4] Davis JD. Comparison of faculty, peer, self and nurse assessment of obstetrics and gynecology residents. Obstet Gynecol 2002;99(4):647-51.

[5] Ryan JG, Mandel FS, Sama A, et al. Reliability of faculty clinical evaluations of non-emergency medicine residents during emergency department rotations. Acad Emerg Med 1996;3(12):1124-30.

[6] Wood J, Collins J, Burnside ES, et al. Patient, faculty and self-assessment of radiology resident performance: a 360-degree method of measuring professionalism and interpersonal/communication skills. Acad Radiol 2004;11(8):931-9.

[7] Risucci DA, Tortolani AJ, Ward RJ. Ratings of surgical residents by self, supervisors and peers. Surg Gynecol Obstet 1989;169(6):519-26.

[8] Johnson D, Cujec B. Comparison of self, nurse and physician assessment of residents rotating through an intensive care unit. Crit Care Med 1998;26(11):18116.

[9] Moore M, Roberts C, Newbury J, et al. Am I getting an accurate picture: a tool to assess clinical handover in remote settings? BMC Medical Education 2017;17(1):213.

[10] Kurtzman ET, Barnow BS. A comparison of nurse practitioners, physician assistants, and primary care physicians' patterns of practice and quality of care in health centers. Med Care 2017;55(6):615-22. 